\title{
LONG-TERM RELIABILITY, BURN-IN AND ANALYSIS OF OUTGASSING IN AU-SI EUTECTIC WAFER-LEVEL VACUUM PACKAGES
}

\author{
Jay Mitchell, G.R. Lahiji, and Khalil Najafi \\ Center for Wireless Integrated Microsystems (WIMS) \\ University of Michigan, Ann Arbor, MI 48109-2122, USA
}

\begin{abstract}
An investigation on outgassing is presented in micro-vacuum packages fabricated using $\mathrm{Au}-\mathrm{Si}$ eutectic bonding. Without getters, package pressures ranging from 2 to 12 Torr were observed-it was shown that these relatively higher micro-vacuum pressures are consistent with outgassing theory. Using Nangetters ${ }^{\mathrm{TM}}$, pressures ranging from 1 to 16 mTorr were achieved. Fourteen devices were kept in a controlled environment and tested for 437 days with $\leq \pm 2$ mTorr variation in pressure. Five devices from this lot were taken out of the controlled environment and incidentally exposed to $40^{\circ} \mathrm{C}$ temperatures and low frequency vibration resulting in wide fluctuations in pressure. Exposing these devices to $150{ }^{\circ} \mathrm{C}$ up to 21 hours served as a "burn-in" step, stabilizing pressures at just above 10 mTorr. Pressures varied by no more than \pm 1 mTorr for the remainder of the 100 hours at $150^{\circ} \mathrm{C}$ and for 50 thermal cycles from -65 to $150^{\circ} \mathrm{C}$.
\end{abstract}

\section{INTRODUCTION}

Low-cost, simple, reproducible, stable hermetic/vacuum packaging technologies are required for many micro-devices such as inertial sensors ( 100 mTorr), infrared sensor arrays (10 mTorr) and micromechanical resonators used in RF applications (10 $\mu$ Torr to 760 Torr). As a result, generic technologies for vacuum/hermetic packaging are needed for these and many other applications.

Vacuum/hermetic packaging of devices has been investigated using a number of approaches including thin film encapsulation, anodic bonding, glass frit bonding and various solder bonding techniques, demonstrating pressures ranging from 1 mTorr to 1 Torr [1-4]. These studies do a very good job of explaining the fabrication process but report very little on reliability testing. A number of companies have also developed vacuum packages and some have reported good long term testing results. Most notably, Raytheon reported stable long term testing results for 940 days at 4 mTorr [4].

Throughout the vacuum science literature, much work has been reported on developing and improving macro-scale vacuum systems and on the study of the effects of outgassing [5, 6]. Here an effort is made to apply some of this theory to micro-cavities $\left(1 \times 10^{-9}\right.$ to $1 \times 10^{-6}$ liters), in particular focusing on outgassing effects. In [1] we presented a wafer-level packaging technique based on Au-Si eutectic wafer bonding, for achieving pressures below 10 mTorr with a yield of $80 \%$ using thin-film Nanogetters $^{\mathrm{TM}}$ [7] (Figure 1). Here, we report on the long-term testing and characterization, outgassing mechanisms, and an essential burn-in technique for maintaining pressures in the milliTorr $(0.1 \mathrm{~Pa})$ range in micro vacuum packages fabricated using Au-Si eutectic bonding. Outgassing was determined as the main obstacle for sustaining low vacuum pressures. Our burn-in technique appears to eliminate outgassing effects, allowing for \pm 1 mTorr pressure stability even after 100 hours at $150^{\circ} \mathrm{C}$ and 50 thermal cycles from -65 to $150^{\circ} \mathrm{C}$.

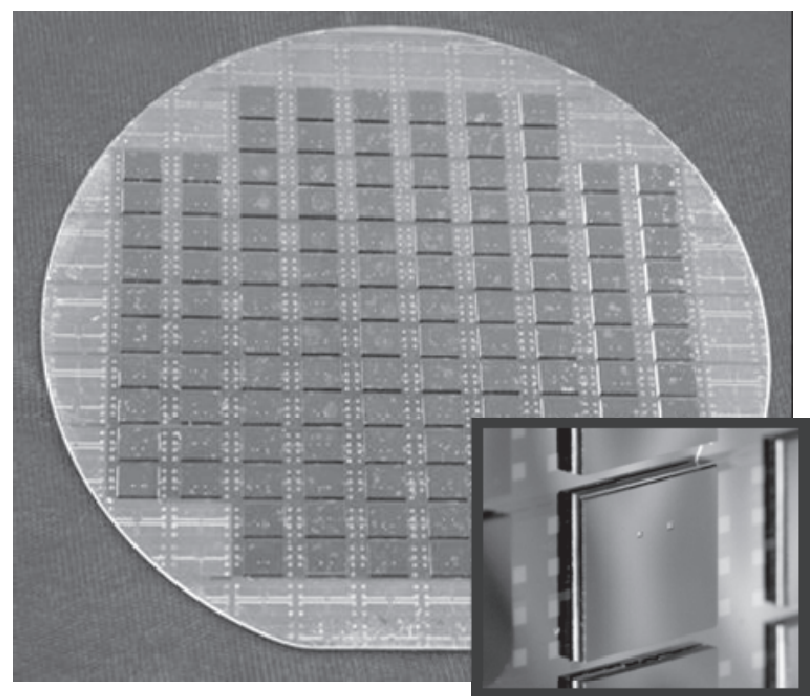

Fig. 1: A wafer with 124 vacuum packaged device and a close up view of one of the packages.

\section{BACKGROUND AND THEORY}

Outgassing involves desorption of materials (such as $\mathrm{H}_{2} \mathrm{O}$, $\mathrm{H}_{2}, \mathrm{~N}, \mathrm{O}$ and $\mathrm{CO}_{2}$ and hydrocarbons) from the inside surface and bulk of vacuum chambers (Figs. 2a and 2b). Extensive investigations have been conducted to determine how to remove these atoms from vacuum systems in order to lower pressures. Typically $\mathrm{H}_{2} \mathrm{O}$ is the dominant outgassing molecule $[5,6]$. In humid environments (such as a cleanroom), hundreds of monolayers of $\mathrm{H}_{2} \mathrm{O}$ can form on the surface of a wafer.

In standard vacuum systems the pressure, $p$, can be calculated as a function of time:

$$
p(t)=\left(p_{0}-\frac{\dot{Q}_{i n}}{S}\right) \cdot \exp \left(-\frac{S}{V} t\right)+\frac{\dot{Q}_{\text {in }}}{S}
$$

where $p_{0}$ is the pressure at the pump, $S$ is the pump speed, $V$ is the volume of the chamber, and $\dot{Q}_{i n}$ is the flow rate into the vacuum chamber. This flow rate is generally dominated by outgassing, $\dot{Q}_{\text {outg }}$ :

$$
\dot{Q}_{\text {outg }}=\frac{a_{1 h} \cdot A}{\left(\frac{t}{1 h}\right)^{\alpha}}
$$

where $A$ is a geometrical factor, and $a_{l h}$ and $\alpha$ are fitting parameters.

In the case of a sealed micro-cavity there is only the net flow into the cavity, $\dot{Q}_{i n}$. Assuming no physical leak path, the pressure, $p$, can be determined as:

$$
p(t)=\int_{0}^{t} \frac{\dot{Q}_{\text {outg }}}{V} d t
$$

Considering Eqs. 1 and 3 the pressure inside a sealed microcavity will be significantly higher than the vacuum chamber it was 
b)

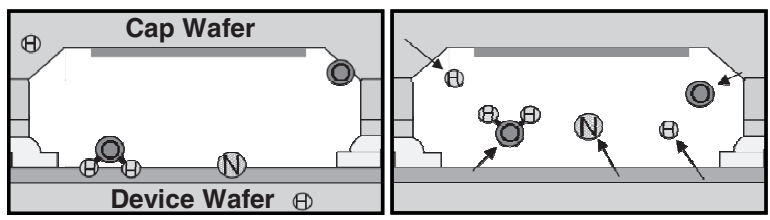

c)

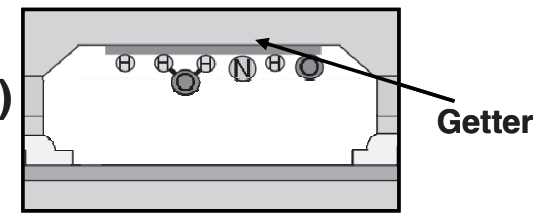

Figure 2: An illustration of a) molecules which have adsorbed on the surface or into the bulk of the micro-vacuum chamber, $\boldsymbol{b}$ ) molecules that desorb off of the chamber walls to increase the pressure and c) these molecules reacting with the getter to lower the package pressure.

sealed in for two reasons: 1) the micro-cavity is not continuously pumped as in the case for Eq. 1, and 2) Eq. 3 shows that for a given surface area, smaller volumes will cause higher pressuresthus the larger surface to volume ratio of micro-cavities causes higher pressures.

As a result, without the use of getters, pressures no lower than 1 Torr have been reported using anodic, solder or frit bonding. Getters are used in macro-scale vacuum systems to aid in achieving lower pressures. They are particularly useful for microscale vacuum packages. Getters work on the principle that metals and alloys such as $\mathrm{Ba}, \mathrm{Al}, \mathrm{Ti}, \mathrm{Zr}, \mathrm{V}$ and Fe react with hydrogen, oxygen, nitrogen and hydrocarbons through oxide and hydride formation [7]. In this manner, as illustrated in Fig. 2c atoms are removed from the vacuum chamber and the pressure is lowered. Getters generally require an "activation step" at an elevated temperature at which the native oxide is dissolved away. For our application, the getter was deposited onto the inside surface of the cap wafer [1], as shown in Fig. 2. Nanogetters ${ }^{\mathrm{TM}}$ [7], provided by ISYSS Corporation, were used in this work.

\section{ANALYSIS OF VACUUM PACKAGING RESULTS}

In the Au-Si eutectic vacuum encapsulation process detailed in [1], cap wafers with Au bond rings were aligned and bonded to device wafers with integrate Pirani (vacuum) gauges at $390^{\circ} \mathrm{C}$. $\mathrm{Si}$ diffuses into the Au layer at above $363{ }^{\circ} \mathrm{C}$ and the Au-Si eutectic forms, melts and adheres to the surface of the device wafer. In a final step, part of the cap wafer is diced away resulting in an array of packages across the wafer (Fig. 1). It is important to note that directly before bonding, the wafers are solvent cleaned and rinsed in water. They then go directly from the $35-40 \%$ humidity of the cleanroom into the SUSS SB6 vacuum bonding chamber. As mentioned earlier, such high exposures to moisture should result in 100s of monolayers of $\mathrm{H}_{2} \mathrm{O}$ [6].

Figure 3 shows the bonding sequence. The chamber is first pumped down to $10 \mu$ Torr. The wafers are held apart using 100 $\mu \mathrm{m}$ spacers at $345^{\circ} \mathrm{C}$ for 1 hour in order to allow for outgassing. (Nanogetters ${ }^{\mathrm{TM}}$ activate around $300^{\circ} \mathrm{C}$, but, because the chamber pressure is only $10 \mu$ Torr, there is very little reaction between the gettering material and the atoms outassing from the wafers and/or chamber). Next the wafers are brought together with $133 \mathrm{kPa}$ of pressure (1000 $\mathrm{N}$ of force). The wafers are then heated to $390{ }^{\circ} \mathrm{C}$ and held at this temperature for 40 minutes.

One set of packages was fabricated without evaporated getters. Initial pressures ranging from 2 to 12 Torr were observed

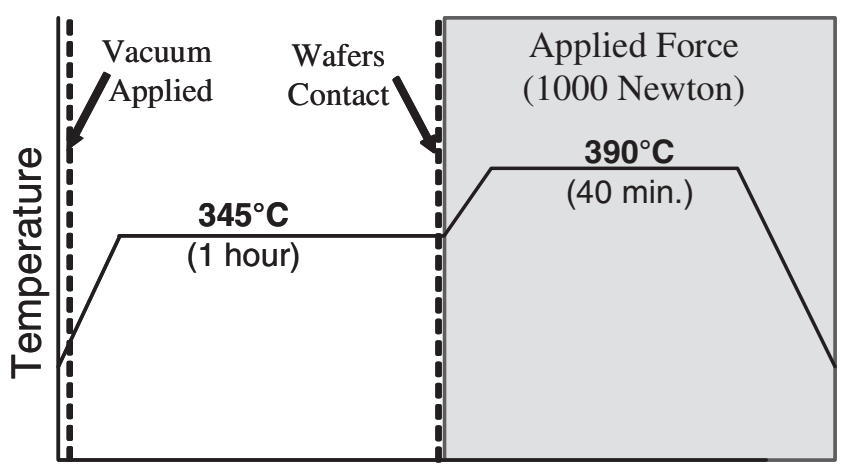

Time

Figure 3: The bonding process used for vacuum packaging.

across the wafer [1] with only a handful of packages showing significant changes in pressure over time. At first glance, it is not intuitive that micropackages sealed in a $10 \mu$ Torr vacuum chamber would have pressures in this range. Considering the exponential relation between the outgassing rate and temperature [5], it is likely that most of the pressure increase happened in the 1 hour the wafers spent heating to, holding at and cooling down from $390{ }^{\circ} \mathrm{C}$ (Fig. 3). The 2 to 12 Torr pressures would correspond to an average outgassing rate per unit area $\left(\dot{Q}_{\text {outg }} / A\right)$ of $3 \times 10^{-9}$ to $2 \times 10^{-8}$

liters-T/ $\mathrm{cm}^{2}$-s during that 1 hour. Considering this outgassing rate, the wafer dimensions, and the speed of the Varion TriScroll Turbo Pump (estimated at $140 \mathrm{~cm}^{3} / \mathrm{s}$ ) in Eq. 1, this level of wafer outgassing should account for, at most, a $1 \mu$ Torr partial pressure. (the rest of the pressure can be accounted for by outgasssing of all of the other surfaces in the bonding chamber).

Figure 4 shows data for packages which showed the largest change in pressure over time, where the pressure was converted to units of outgassing rate (liters $\bullet$ Torr/[ $\left[\mathrm{s}^{\bullet} \mathrm{cm}^{2}\right]$ ) and graphed verses time. These packaged pressures went from 10 to 14 Torr and 12 to 27 Torr over a 235 day period. The graphs in Fig. 4 exhibit the power law decay typical for outgassing (Eq. 2). The observed $\mathrm{n}=1.5$ behavior was shown to indicate a high exposure to humidity by M. Li et al. [6]. Furthermore, it should be noted, that the outgassing rates in Fig. 4 are significantly smaller than those in a typical macro-scale vacuum chamber. In $\mathrm{M}$. Li et al. [6], for example, it took 200 hours of pumping at room temperature, to reach a $\dot{Q}_{\text {outg }} / A$ of $5 \times 10^{-11}$ liters-T/ $\mathrm{cm}^{2}$-s for a 16 liter chamber exposed to various levels of humidity.

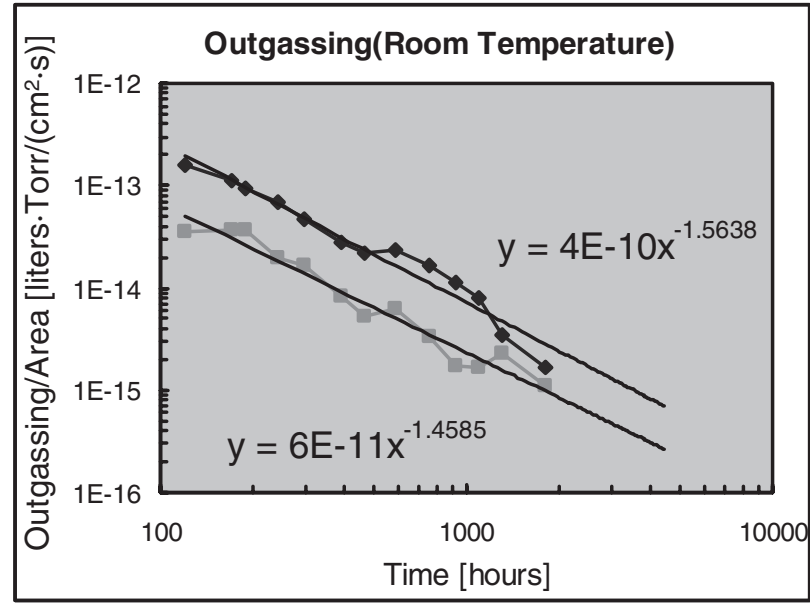

Figure 4: A graph illustrating the outgassing rates for two packages which were packaged without getters. These packages went from 10 to 14 Torr and 12 to 27 Torr in a 235 day period. 


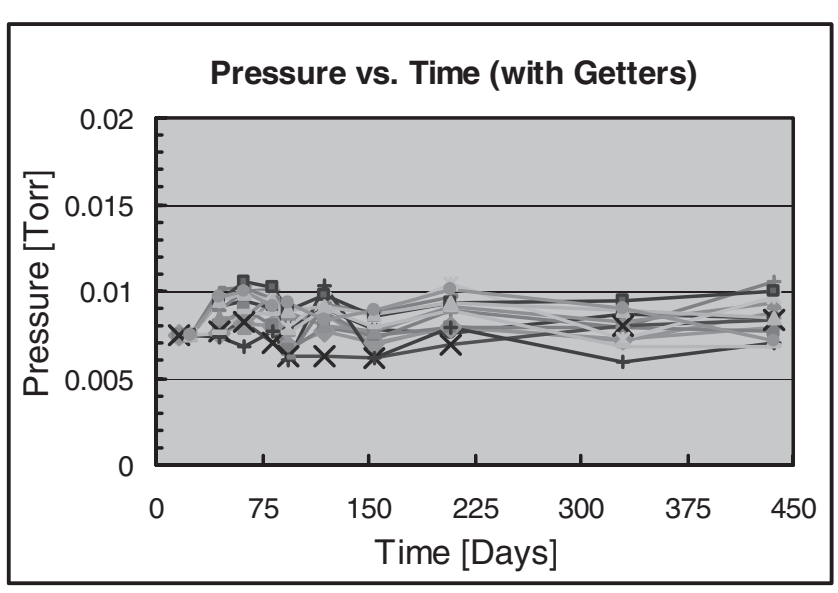

Figure 5: Data for fourteen packages which were tested in a controlled environment (minimal vibration and temperature fluctuation) resulting in less than \pm 2 mTorr pressure fluctuation.

In another set of packaged devices, pressures from 1 to 16 mTorr were achieved by encapsulating Nanogetters ${ }^{\mathrm{TM}}$ inside each of the micropackages. This is nearly a $10^{3}$ times decrease in pressure with the addition of Nanogetters ${ }^{\mathrm{TM}}$. Figure 5 shows data for 14 devices in which testing continued for an additional 437 days after packaging in a controlled environment (i.e. limited vibration/shock, temperatures of $23 \pm 2{ }^{\circ} \mathrm{C}$, etc.). Less than \pm 2 mTorr pressure fluctuation was observed.

Figure 6 shows data from 5 packages (packages 1-5) that were taken out of the controlled environment after 200 days of testing. These devices were exposed to low frequency vibration and temperatures up to $40^{\circ} \mathrm{C}$ due to transit. Increases in pressure were almost certainly due to outgassing (desorbtion of gasses from cavity walls) and subsequent decreases in pressure were likely due to gettering (reaction of trapped gasses with the getter).

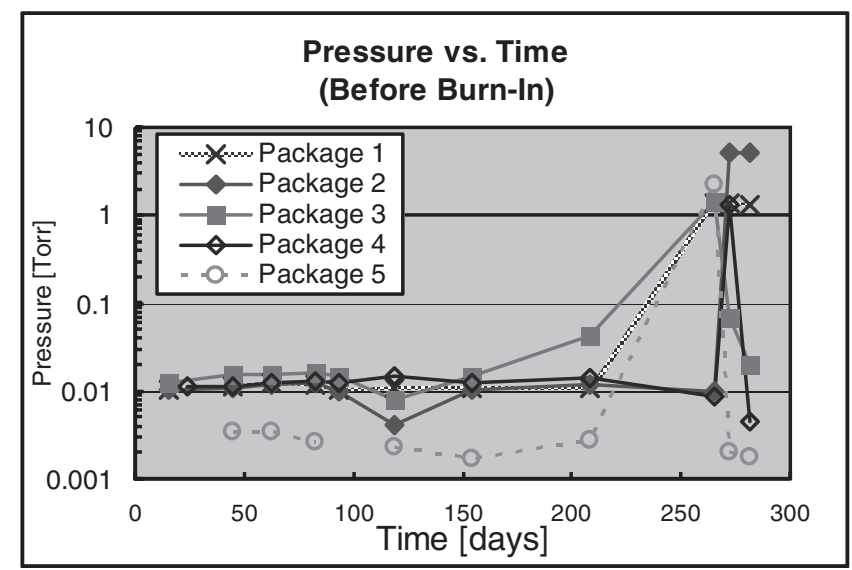

Figure 6: Five packages which were taken out of the controlled environment (after 200 days). Large pressure fluctuations were observed due to outgassing and gettering.

\section{TEMPERATURE RAMPING AND BURN IN}

Temperature ramping tests were conducted inside of a Tenney Temperature Benchtop oven/refrigeration system. A schematic of the test setup is shown in Fig. 7. Individual packages (as shown in the inset of Figure 1) were diced, mounted and wire bonded to dual-inline packages (DIPs). During testing, these DIPs were plugged into high temperature PC board which sat inside of the oven. Leads from the PC board ran to a switch box, which allowed for individual testing of each of 9 vacuum packages. Vacuum pressures were determined using a computer controlled program to direct currents across the Pirani gauges while measuring the voltage drop across them. From this data, the thermal impedance was measured and a calibration curve was used to convert thermal impedances into pressures. The test methodology for our Pirani gauges are detailed elsewhere [8].

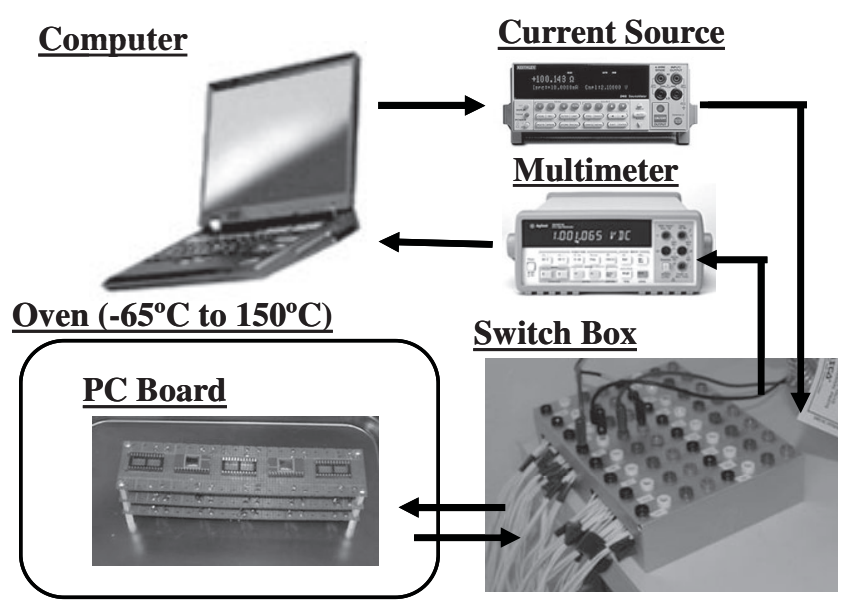

Figure 7: Packaged vacuum sensors were tested inside of an oven using a labview program, a current source, a multimeter and a switch box to test each sensor during and ever ramping cycles.

Temperature ramping and cycling tests were conducted on the 5 devices from Fig. 6, along with 4 packages without getters (a control sample). Temperatures were first raised to 50, 75, 100 and $125^{\circ} \mathrm{C}$ and held for 1 to 2 hours. As shown in Figures 8 and 9, the temperature was then raised to $150^{\circ} \mathrm{C}$ for 100 hours, then to $-65^{\circ} \mathrm{C}$ for 7.5 hours and then thermal cycled from -65 to $150^{\circ} \mathrm{C}$ for 50 thermal cycles (well exceeding the requirements for MIL-SPEC883F Method 1010.8 for thermal cycling). Packages 1, 3, 4 and 5 stabilized during the $50^{\circ} \mathrm{C}$ and $125^{\circ} \mathrm{C}$ bakes, whereas package 2 stabilized after 21 hours in the $150^{\circ} \mathrm{C}$ bake, all at just above 10 mTorr. As shown in Fig. 8, for the remainder of the 100 hour at $150^{\circ} \mathrm{C}$, the 7.5 hours at $-65^{\circ} \mathrm{C}$ and the 50 thermal cycles from -65 to $150^{\circ} \mathrm{C}$, pressure fluctuations of smaller than \pm 1 mTorr were measured. On the other hand, Fig. 9 shows that for the packages without getters (packages 6-9) pressures only continue to increase with time.

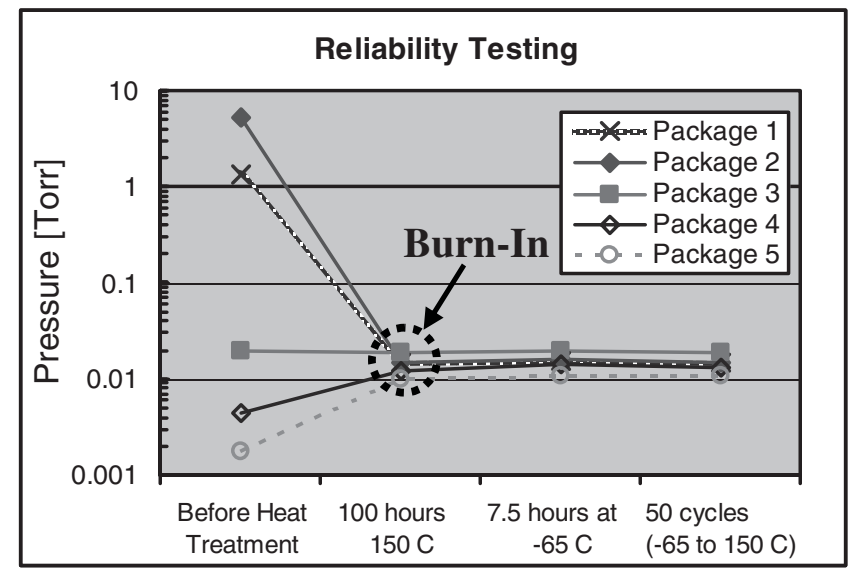

Figure 8: After heat treatment, pressures stabilized in the packages from Figure 6. Pressures continued to be stable even after 100 hours at $150^{\circ} \mathrm{C}$ and thermal cycles from -65 to $150{ }^{\circ} \mathrm{C}$. 


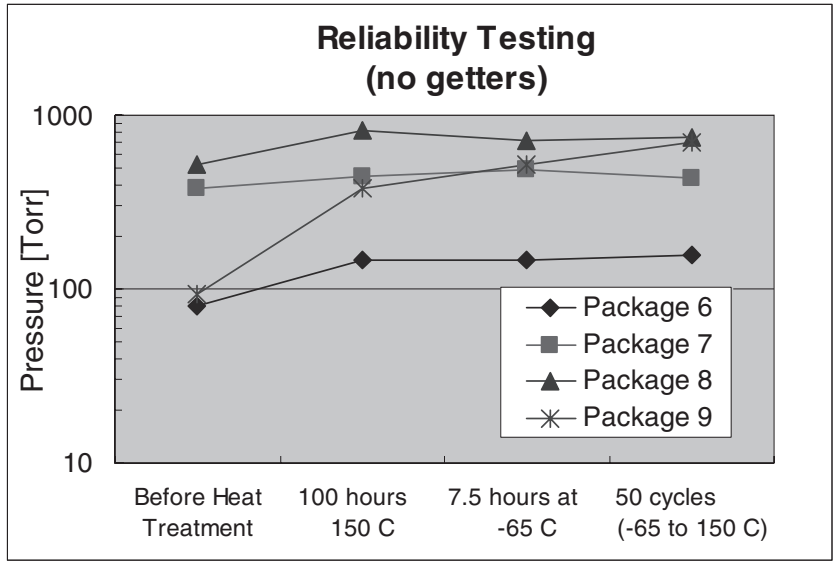

Figure 9: The pressures in packages without getters continue to rise with temperature treatment.

In all of the packages, elevated temperatures likely drove out atoms from the surface and bulk of the package cavities (i.e. causing outgassing as illustrated Fig. 2b) causing the increases in pressure seen in Figs. 6, 8 and 9. This increase in temperature should also provided extra energy for chemisorption of gases into the getter (i.e. gettering as illustrated in Fig. 2c), causing the pressure to fall in packages with getters. These competing effects explain the fluctuations seen in Figs. 6 and 8. Holding packages 15 at an elevated temperature for an extended period in Fig. 8 appears to have caused a majority of the adsorbed atoms to desorb from the inside cavity surface and then react with the getter-thus stabilizing the package pressure. Such temperature treatment could serve as a "burn-in," step in order to guarantee future pressure stability.

Figure 10 shows temperature ramping data for two of the packages that were packaged without getters. In this graph, the pressures are corrected for the ideal gas law $(\mathrm{PV}=\mathrm{nRT})$. As shown, temperatures from $50^{\circ} \mathrm{C}$ to $150^{\circ} \mathrm{C}$ caused packages without getters to permanently increase in pressure-thus implying outgassing. Cooling to $-65^{\circ} \mathrm{C}$ on the other hand, caused a temporary reduction in pressure, suggesting condensation of outgassed molecules.

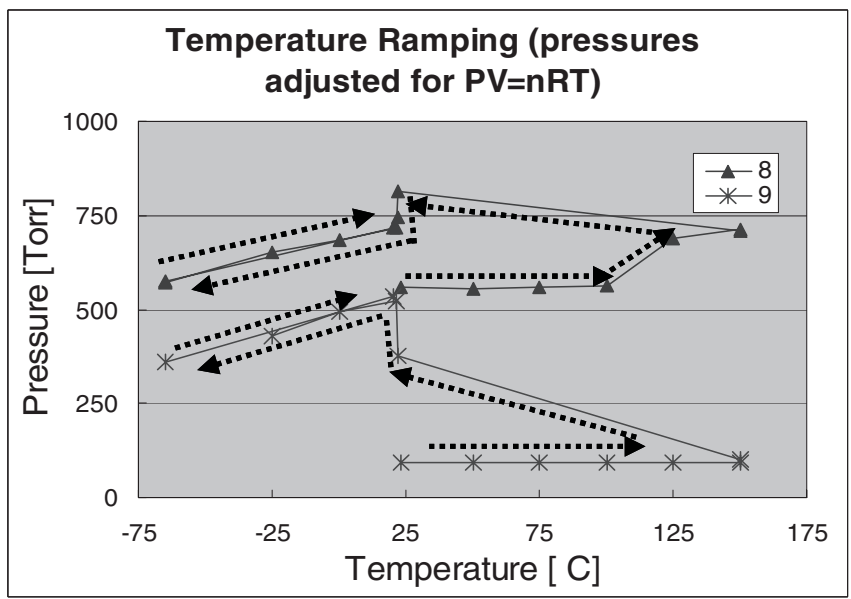

Figure 10: Temperature ramping data for two devices packaged without getters, from Figure 4, illustrating irreversible pressure increase (outgassing) from 50 to $150{ }^{\circ} \mathrm{C}$, and reversible pressure change (condensation) from 0 to $-65^{\circ} \mathrm{C}$.

\section{CONCLUSION}

An investigation on outgassing was conducted on microvacuum packages fabricated using $\mathrm{Au}-\mathrm{Si}$ eutectic bonding. Packages without getters, sealed at $10 \mu$ Torr, ended up with pressures ranging from 2 to 12 Torr. It was shown that these higher micro-vacuum pressures are consistent with outgassing theory. Using Nangetters ${ }^{\mathrm{TM}}$, pressures ranging from 1 to 16 mTorr were achieved - a roughly $10^{3}$ times reduction in pressure. Fourteen devices from the same lot were kept in a controlled environment, demonstrating pressure fluctuations of $\leq \pm 2$ mTorr in 437 days of testing. Five devices from this lot were exposed to $40^{\circ} \mathrm{C}$ temperatures and low frequency vibration, in transit, thereafter showing wide fluctuations in pressure. Exposing these packages to $150{ }^{\circ} \mathrm{C}$ for up to 21 hours, all of the package pressures stabilized at just above 10 mTorr and remained stable for the remainder of the 100 hours at $150^{\circ} \mathrm{C}$ and for 50 thermal cycles from -65 to $150^{\circ} \mathrm{C}$. It is suggested that such heat treatment could be used as a "burnin" step in order to drive out surface molecules in micro-vacuum packages and provide extra energy for chemisorption of these molecules into the getter. Further study of these phenomena though is required.

\section{ACKNOWLEDGMENTS}

This work was supported in part by the Engineering Research Centers Program of the National Science Foundation under Award Number EEC-9986866, and in part by DARPA's HERMIT program under contract number W31P4Q-04-1-R001. We thank Sandia National Laboratories and Dr. Bernie Jokiel for the use of environmental chambers. Nanogetters ${ }^{\mathrm{TM}}$ were deposited by Integrated Sensing Systems (ISSYS).

\section{REFERENCES}

[1] J. Mitchell, G. R. Lahiji, and K. Najafi, "Encapsulation of vacuum sensors in a wafer level package using a gold-silicon eutectic," Tech Digest, Transducers'05, Seoul, Korea, 928931 (2005).

[2] R.N. Candler, W.T Park, M. Hopcroft, B. Kim, T.W. Kenny, "Hydrogen diffusion and pressure control of encapsulated mems resonators," Tech Digest, Transducers'05, Seoul, Korea, 920-923 (2005).

[3] B.H. Stark and K. Najafi, "A low-temperature thin-film electroplated metal vacuum package," J. Microelectromech Syst, 13, 147-157 (2004).

[4] R. Gooch and T. Schimert, "Low-cost wafer-level vacuum packaging for MEMS," MRS Bulletin, 28, 55-59 (2003).

[5] J. M. Lafferty, Vacuum Science and Technology, John Wiley \& Sons, Inc., 507-546, 1998.

[6] M. Li and H.F. Dylla, "Model for the outgassing of water from metal surfaces," J. Vac. Sci. Technol. A, Vol. 11, No. 4, 1702-1707 (1993).

[7] D.R. Sparks, N. Najafi and S. Massoud-Ansari, "Chip-Level Vacuum Packaging of Micromachines Using Nanogetters," IEEE Transactions on Advanced Packaging, 26, 277-282 (2003).

[8] J.S. Mitchell, G.R. Lahiji and K. Najafi, "An Improved Performance Poly Si Pirani Vacuum Gauge Using Heat Distributing Structural Supports," Proc. of IEEE MEMS Conf. 291-294 (2005). 